\title{
Retraction Note to: Role of RASSF 1A promoter methylation in the pathogenesis of hepatocellular carcinoma: a meta-analysis of 21 cohort studies
}

\author{
Yong-Shuang $\mathrm{Li}^{1} \cdot$ Qiang Xie $^{1} \cdot$ Da-Ye Yang ${ }^{1} \cdot$ Yuan Zheng $^{1}$
}

Published online: 18 August 2015

(C) Springer Science+Business Media Dordrecht 2015

\section{Retraction Note to: Mol Biol Rep (2014) 41:3925-3933}

DOI 10.1007/s11033-014-3260-0

The Publisher and Editor retract this article in accordance with the recommendations of the Committee on Publica tion Ethics (COPE). After a thorough investigation we have strong reason to believe that the peer review process was compromised.

The online version of the original article can be found under doi:10.1007/s11033-014-3260-0.

Yong-Shuang Li

cmu4h_lys@163.com

1 Department of Emergency Surgery, The Fourth Affiliated Hospital of China Medical University, Chongshan East Road No. 4, Huanggu District, Shenyang 110032,

People's Republic of China 